\title{
Report
}

\section{Diagnosis of Fungal and Bacterial Diseases Based on Symptom \& Sign}

\section{Yitagesu Tadesse Demissie}

Department of Plant Pathology, Holleta Agricultural Research Centre, Ethiopian Institute of Agricultural Research, Addis Ababa, Ethiopia

\section{Email address:}

tyitagesu4@gmail.com

\section{To cite this article:}

Yitagesu Tadesse Demissie. Diagnosis of Fungal and Bacterial Diseases Based on Symptom \& Sign. American Journal of Plant Biology. Vol. 4, No. 4, 2019, pp. 57-66. doi: 10.11648/j.ajpb.20190404.12

Received: May 23, 2019; Accepted: July 11, 2019; Published: October 16, 2019

\begin{abstract}
Plant disease diagnosis is a form of hypothesis testing, where the hypothesis is simply the identity of the disease, and a good diagnostician goes through multiple iterations of the scientific method (seeking evidence through testing that supports or refutes the hypothesis that $\mathrm{s} / \mathrm{he}$ generates). Identification of affected plants is one of the first steps in diagnosing a plant disease. Diagnosis is one of the most important aspects of a plant pathologist's training. Both scientific and common names of the plant should be noted. Without proper identification of the disease and the disease-causing agent, disease control measures can be a waste of time and money and can lead to further plant losses. Fungi are small, generally microscopic, eukaryotic, usually filamentous, branched, spore-bearing organisms that lack chlorophyll. Bacteria are prokaryotes. These are generally single-celled microorganisms whose genetic material (DNA) is not bound by a membrane and therefore is not organized into a nucleus. Our general objective was to acquaintance with Plant pathology laboratory materials \& make disease diagnosis from field up to laboratory based on symptom and signs from different plant samples. All most all necro-tropic and bio-tropic fungi are grown on PDA agar, but bio-tropic fungi and bacterial diseases cannot grow on PDA agar. The best preferable method to diagnosis bio-tropic fungi is using direct leaf assay and blotting method on petri-dish. For bacterial disease identification we use NA agar. From this laboratory work I had concluded that those fungal and bacterial diseases need their niche to grow and well identified. It is very difficult to identify plant diseases based on sign and symptom. It is very imperative to diagnosis plant disease by collaborating both conventional (using sign and symptom) and molecular methods. It needs further work to identify rust diseases using race analysis up to $f$. species level.
\end{abstract}

Keywords: Diagnosis, Identification, Symptom, Sign, Fungus, Bacteria

\section{Introduction}

Plant disease diagnosis is a form of hypothesis testing, where the hypothesis is simply the identity of the disease, and a good diagnostician goes through multiple iterations of the scientific method (seeking evidence through testing that supports or refutes the hypothesis that $\mathrm{s} /$ he generates) [1-2]. These hypotheses are generated through observations of the plant, environment, and information from the grower. When all of the information is successfully collected, literature sources should be consulted to determine what is already known about diseases and disease-causing agents associated with the identified plants and helps to the application of effective management practices.
Identification of affected plants is one of the first steps in diagnosing a plant disease [3-4]. Both scientific and common names of the plant should be noted. Common names should not be relied upon since some distinctly different plant species may have the same common name, and the common name used in one area may be used for a completely different species in another area. Obviously the use of common names can cause confusion in identification and recognition of problems [5]. In addition to knowing the common and scientific names of an affected plant, it is important to know the specific variety or cultivar, whenever possible. A great variation in susceptibility to a specific disease may occur within different cultivars of a plant species [6]. The diagnostician must have very good observation skills, and s/he also needs to be a good 
detective [7]. It is important to keep an open mind until all of the facts related to the problem can be collected. The possibility of multiple causal factors must also be considered. Control measures depend on proper identification of diseases and of the causal agents [8]. Therefore, diagnosis is one of the most important aspects of a plant pathologist's training. Without proper identification of the disease and the disease-causing agent, disease control measures can be a waste of time and money and can lead to further plant losses. Proper disease diagnosis is therefore vital [1].

Fungi are small, generally microscopic, eukaryotic, usually filamentous, branched, spore-bearing organisms that lack chlorophyll. Fungi have cell walls that contain chitin and glucans (but no cellulose) as the skeletal components. These are embedded in a matrix of polysaccharides and glycol proteins. Most of the more than 100,000 known fungus species are strictly saprophytic, i.e., they live on dead organic matter, which they help decompose. More than 10,000 species of fungi, however, can cause disease in plants. All plants are attacked by some kinds of fungi, and each of the parasitic fungi can attack one or many kinds of plants. Some fungi, known as obligate parasites or biotrophs, can grow and multiply only by remaining, during their entire life, in association with their host plants. Others, known as non-obligate parasites, require a host plant for part of their life cycles but can complete their cycles on dead organic matter, or they can grow and multiply on dead organic matter as well as on living plants [9].

Bacteria are prokaryotes. These are generally single-celled microorganisms whose genetic material (DNA) is not bound by a membrane and therefore is not organized into a nucleus. Their cells consist of cytoplasm containing DNA and small $(70 \mathrm{~S})$ ribosomes. About 100 species of bacteria cause diseases in plants. Most plant pathogenic bacteria are facultative saprophytes and can be grown artificially on nutrient media; however, fastidious vascular bacteria are difficult to grow in culture and some of them have yet to be grown in culture [10].

\subsection{Preparation of Culture Media Potato Dextrose Agar (PDA) for Fungi and Nutrient Agar (NA) for Bacteria}

Medium (media pl.) is the substance which provides nutrients for the growth of microorganisms. The nutrient preparation on which culture is grown in the laboratory is called culture medium Microbes require different nutrients for their growth. There is no single medium which can support the growth of majority of microbes [27-28].

Natural medium: The exact chemical composition of this media isn't known properly. It includes ingredients of natural origin like yeast extract, beef, milk, tomato juice, blood etc.

Semi-synthetic: The chemical composition of media is only partially known. Media, which contains Agar, is semi-synthetic medium.

Synthetic medium: The chemical composition of the medium is completely known. These media are very useful in studying the physiology, metabolic nature and nutritional requirements of microbes. Both autotrophs and heterotrophs can be grown in these media.

\subsection{Identification of Major Maize Cob Diseases Samples Collected from SNNP Region and Jimma District}

Maize (Zea mays L.) is grown under a diverse range of climate and cropping conditions [29]. In the southernmost subtropical climate, maize is a typical summer crop, succeeding small-grain cereal crops. Several diseases potentially limit maize yields, such as those affecting leaves, stalks and ears, and are caused by several pathogenic fungi [31-32]. Ear rots caused by various fungi, including Fusarium species, contribute to poor grain quality and contaminate grains with mycotoxins, which represent a threat to both human and animal health [32-34]. Climatic conditions and crop management practices, such as crop rotation, tillage, planting date and fertilization, influence the occurrence and prevalence of the Fusarium species that affect maize [35].

\subsection{Diagnosis of Bacterial and Fungal Diseases of Plant}

Most plant diseases - around 85 percent - are caused by fungal or fungal-like organisms [36-37]. However, other serious diseases of food and feed crops are caused by viral and bacterial organisms. Certain nematodes also cause plant disease. Some plant diseases are classified as "a biotic," or diseases that are non-infectious and include damage from air pollution, nutritional deficiencies or toxicities, and grow under less than optimal conditions. In diagnosing problems of plants from the production area, the retail area, the landscape, or home all the possible causes of poor or abnormal growth must be considered [38-39].

\subsection{Diagnosis of Fungal and Bacterial Diseases in Laboratory Under Class Basidiomycetes (Rust and Smut); Powdery Mildew and Zygomycetes}

Basidiomycetes include two very common and very destructive groups of plant pathogenic fungi that cause the rust and Plant smuts, caused by Basidiomycetes of the order Ustilaginales, occur throughout the world [40-41]. There are approximately 1,200 species of smut fungi. Until the 20th century, smuts were the causes of serious grain losses that were equal to, or second only to, losses caused by the rusts. In some respects, the smuts of cereals were dreaded by farmers even more than rusts because many smuts attack the grain kernels themselves and replace the kernel contents with the black, dusty Spore masses that resemble soot or smut [42]. Plant rusts, caused by Basidiomycetes of the order Uredinales, are among the most destructive plant diseases. They have caused famines and ruined the economies of large areas, including entire countries [43-44].

Fungi causing powdery mildews are obligate parasites: they cannot be cultured on artificial nutrient media, but recently the powdery mildew fungus of barley, Blumeria graminis f. sp. hordei, was grown in culture. They produce mycelium that grows only on the surface of plant tissues but does not invade the tissues themselves. Powdery mildews are 
probably the most common, conspicuous, widespread, and easily recognizable plant diseases. They affect all kinds of plants except gymnosperms. Powdery mildew is most common on the upper side of leaves, but it also affects the underside of leaves, young shoots and stems, buds, flowers, and young fruit [45].

The other Plant pathogenic fungal group is Zygomycetes which are weak parasites. This is characterized by well-developed mycelia without cross walls and produce non motile spores in sporangia; their resting spore is a thick-walled zygospore produced by the union of two morphologically similar gametes. Zygomycetes are strictly terrestrial fungi, their spores often floating around in the air, and are either saprophytes or weak parasites of plants and plant products on which they cause soft rots or molds. Some, e.g., Rhizopus, are opportunistic pathogens of humans. Plant pathogenic Zygomycetes are weak parasites. They grow mostly as saprophytes on dead or processed plant products; even when they infect living plant tissues, they first attack injured or dead plant parts. The mycelium then grows into and colonizes the tissues it killed [46].

\subsection{Bacterial Disease Diagnosis in Laboratory}

Bacteria are minute one-celled microbes closely related to fungi. Plant pathogenic bacteria do not produce spores. They reproduce by simple cell division. The tiny rod-shaped cells reproduce very rapidly. Cells may divide every 20 to 30 minutes. At this rate, one cell will give rise to 17 million cells in 12 hours. This rapid growth rate accounts for the seemingly explosive nature of bacterial diseases. Large cell numbers confer great bacterial cell surface area for release of enzymes, toxins, or slime. These bacterial products are responsible for much of the damage caused by bacterial infection [47].

Bacteria Spread by blowing rain: Bacteria ooze out of infected tissue and form a mass of sticky material on the plant surface. Rain drops hit the bacteria and splatter them to new infection sites. Insects: In the process of pollinating plants, bees crawl through the bacterial ooze and then deposit the organism in blooms. This is the primary means of spreading fire blight of apple and pear from tree to tree. Some bacteria live inside insect vectors and are spread from plant to plant. People: While picking beans or suckering tomatoes, people can come in contact with bacteria and transfer them from plant to plant on their hands. Never work in the garden when plants are wet. Seed: Bacteria can live from year to year inside seeds. When infected seeds are shared between gardeners, bacterial diseases can spread. This is why seeds grown in a dry western climate are clean. Avoid saving seeds from your garden unless you are preserving a unique variety [6].

General Objective:

Acquaintance with Plant pathology laboratory materials \& make disease diagnosis from field up to laboratory based on symptom and signs from different plant samples.

Specific Objectives:

1. To familiarize with Plant pathology laboratory equipment and materials for use them properly in disease diagnosis.

2. To know how media prepare and use for growing different pathogen isolates.

3. Differentiating \& diagnosing different group of diseases that affect maize cob ear diseases such as Fusarium, Aspergilous, Pencillium, Rhizopous and determine which is most dominance from the listed and their combination.

4. To visualized and differentiate the structural difference between spore and mycelium of different fungal class (rust, smut and powdery mildew) Basidiomycetes, Ascomycets, Zygomycetes, etc under microscopes.

5. Observe the samples which are collected from different plants which are infected with different diseases and identify their symptoms and signs.

6. To identify the causative agent of rust under class basidiomycetes.

7. To familiarize with us the structural difference of rhizopus both from bread mold and culture media under class zygomycetes.

\section{Materials and Methods}

\subsection{Acquaintance with Plant Pathology Laboratory \& Equipment's}

\section{Microscope}

Microscope is a device, which can magnify a microbial cell or a group of microbial cells to enable the human eye to study its structures, morphology e.t.c [11].

A. Simple microscope: Consists of a simple lens system.

B. Compound microscope: It consists of 2 or more lens systems- Depending on source of illumination, they are of two kinds.

2. Autoclave

Microbes are killed at $121^{\circ} \mathrm{C}$ and $151 \mathrm{~b}$ pressure per sq. inch in $15 \mathrm{~min}$. It is more efficient and common instrument used to sterilize solids and liquid media for microbial culture. The materials to be sterilized are kept in a basket provided with holes all around for the free circulation of steam [12].

3. Pressure cooker

It is a suitable alternative to an autoclave. In case of power failure materials are sterilized in pressure cooker [13].

4. Hot air oven

It is an electrically operated equipment with a thermostat (ambient Temp, to $300^{\circ} \mathrm{C}$ ) used for sterilizing glassware [14].

5. Incubator

It is used for incubation (culturing of microbes) at a constant temp [15].

6. Colony counter

It is an electronic apparatus used to count the number of colonies on a Petri plate [16].

7. Inoculation chamber

Most of the aseptic transfers are made using inoculation chamber made of wood. It is used for reducing danger of infection while working with infective microorganisms and for preventing contamination of sterile materials. 


\section{Ultraviolet lamps}

The lamp which produces U. V. rays of near 200-300 nm wavelength kill or inactivate most of the virus and vegetative form of microorganism present in laboratory or on an inoculation chamber [17].

\section{9. $\mathrm{PH}$ meter}

It is used to determine the $\mathrm{pH}$ of solutions of unknown $\mathrm{pH}$ as well as for setting of $\mathrm{pH}$ of various media, and testing biochemical activity of microorganism. The optimum range of $\mathrm{pH}$ for bacteria is 6.5 to 7.5 and for fungi it is 4-6 [18].

10. Water bath

It is an insulated metallic box fitted with an electric heating mechanism and a thermostat, which maintains the temperature at desired level [19].

11. Centrifuge

It is an apparatus that rotates at high speed and separates substances as particles on the basis of mass and density by means of centrifugal force. The commonly used centrifuges are of low speed, high speed and ultracentrifuge with highest speed limit of $5000 \mathrm{rpm}, 18000 \mathrm{rpm}$, and 20,000 to 60,000 rpm, respectively [20].

\section{Balance}

Various media components for culture media preparation and samples e. t. c. are weighed on an ordinary balance.

13. Spectrophotometer or colorimeter

It is an electrically operated simple instrument used for estimating population of bacteria, based on the principle of turbidity determination [21].

14. Haemo cytometer

The number of microorganisms present in a given liquid sample can be counted and morphology of bacteria can be observed by direct cell count method using haemo-cytometer [22].

\section{Filters}

Heat sensitive materials like vitamin solutions are sterilized by filtration technique as they are destroyed by heating at temperature normally used [23].

16. Refrigerator

It is a basic requirement in the microbiological laboratory and used for storing stock cultures of microorganism at $4{ }^{\circ} \mathrm{C}$ to save sub-culturing every few days [24].

\section{Bunsen Burner}

It is a type of gas burner with which a very hot particularly non-luminous flame is obtained by allowing air to enter at the base and mix with gas. In the absence of Bunsen burner, alcoholic lamp is used. They are used to sterilize inoculation needles / loops before they are inserted into culture [25].

18. Hot plate stirrer

It is useful to stir the chemicals in water without heat to make suspension. It is fined with the stirrer and heat control. Stirring is done by creating magnetic field, which causes the bar magnet kept in the container to spin resulting in the stirring [26].

\subsection{Preparation of Culture Media Potato Dextrose Agar (PDA) for Fungi and Nutrient Agar (NA) for Bacteria Preparation of Basic Solid Medium}

Liquid broth media containing nutrients are usually solidified by the addition of agar.

A. Preparation of Potato Dextrose Agar Medium: Used in isolation and maintenance of common fungi.

Materials: Peeled potatoes - 200g, Dextrose - 20 g. Agar $20 \mathrm{~g}$, Distilled water 1L, beaker 1L, $250 \mathrm{ml}$ conical flasks, knife, muslin cloth, measuring cylinder, cotton non-absorbent, pressure cooker.

Procedure

1. Take $500 \mathrm{ml}$ of distilled water in $1 \mathrm{~L}$ beaker and add $200 \mathrm{~g}$ of peeled and sliced potato boil the potatoes till they become soft.

2. Filter the contents of the beaker through muslin cloth and squeeze out all liquid.

3. Add the dextrose dissolved in water to this extract.

4. Adjust the $\mathrm{pH}$ of medium to 6 to 6.5 using $0.1 \mathrm{~N} \mathrm{HCl}$ or $0.1 \mathrm{~N} \mathrm{NaOH}$ as the ease maybe.

5. Add the dissolved agar to dextrose-potato extract and make the volume to $1 \mathrm{lt}$ and dispense $200 \mathrm{ml}$ each to 5 conical flasks and plug with non-absorbent cotton-Sterilized the flasks at $15 \mathrm{Ibs}$ pressure for 15 minutes in a pressure cooker.

6. Allow the pressure cooker to cool, "Remove the conical flask and store at room temperature. Allow the flask to cool until the flask can be held by hand.

7. Prepare agar plate by pouring the media into Petri-dish quickly. Using aseptic condition, allow the media in Petri-dish to solidify to produce the agar plate.

B. Preparation of Nutrient Agar Medium: Used for the maintenance and isolation of bacteria.

Materials: peptone - 5g, beef extract - 3g, Agar - 20g, distilled water -1lt, Petri-dish, 1lt beaker, $250 \mathrm{ml}$ conical flasks, measuring cylinder, non- absorbent cotton, pressure cooker and hot plate.

Procedure

1. Dissolve the weighed amounts of peptone and beef extract into $500 \mathrm{ml}$ of water.

2. Heat and dissolve the chemicals and adjust the $\mathrm{pH}$ of medium to 7 by adding $0.1 \mathrm{~N} \mathrm{HCl}$ or $0.1 \mathrm{~N} \mathrm{NaOH}$.

3. Weigh $20 \mathrm{~g}$ agar and dissolve in $500 \mathrm{ml}$ of distilled water in another beaker.

4. Mix the dissolved agar with chemical solution and make up the vol. to 11 t.

5. Dispense $200 \mathrm{ml}$ each into 5 conical flasks.

6 . Plug the flask with non- absorbent cotton and sterilize at $15 \mathrm{Ibs}$ pressure for 15 minutes in a Pressure cooker.

7. Allow the cooker to cool, remove the conical flask and store at room temp, or.

8. Allow the flask to sufficiently cool and prepare agar plates by pouring media into Petri-dish under aseptic condition; allow the media with Petri-dish to solidify.

\subsection{Identification of Major Maize Cob Diseases Samples Collected from SNNP Region and Jimma District}

Sample of the stored maize grain was collected at altitude of the area raging from $100-3800 \mathrm{~m}$. a. s. 1 . and then before performing any activities under laboratory in lamina flow each and every materials were sterilized with $70 \%$ of alcohol. 
Materials used in laboratory to grow the pathogens includes; 100 maize grains which are infected with diseases, Petri-dishes, lamina flow, ethanol, distilled water, forceps, tries which are used for pathogen growth on them, plastic sheet for covering of tries, marker which is used for labeling on try the name of the sample. Which were contains 100 maize grains and it was added in to the first Petridis which contains $70 \%$ of alcohol. And then it was turned into the next two and three consecutive Petridish that contains sterilized distilled water with the aid of forceps. And it was distributed on filter pepper. And $60 \mathrm{ml}$ of sterilized distilled water was added on displayed drain. Finally, the sterilized 100 maize grains were displayed on sterilized drain with uniform distribution and it was leveled. Then the drain was covered with transparent film plastics and fixed with plaster and it was incubated for 10 days and the developments of ear rots were observed and the infected kernel frequency was calculated.

Procedures used for maize ear pathogens identification by moist chamber growing includes the following:

i. Prepare four Petri-dishes and add $75 \%$ ethanol on the first dish, add sterilized distilled water to the next three petri-dishes for disinfecting saprophytes on the maize cobs. Sterilization is the most important step in plant pathological experiment.

ii. Dry the sterilized maize cobs samples on filter pepper for minimizing moisture of outer seed water for accurate sample plating using sterilized forceps.

iii. Put pepper on tries and moist those using distilled water put 100 maize grains uniformly with equal spacing between grains to increase diagnosis accuracy.

iv. Labeling the sample name, date of plating the sample, name of person who plate them, seal with plaster and put the sample in incubator up to the pathogen growth begin for identification.

v. Maize grain diseases identification based on disease symptom and sign.

vi. Count the incidence of different diseases and score them, after that interpret the result.

vii. The interpretation was done using frequency of kernel infection from the total kernel numbers.

Sample of the stored maize grain was collected at altitude of the area raging from $100-3800 \mathrm{~m}$. a. s. 1. and then before performing any activities under laboratory in lamina flow each and every materials were sterilized with $70 \%$ of alcohol.

Materials used in laboratory to grow the pathogens includes; 100 maize grains which are infected with diseases, Petri-dishes, lamina flow, ethanol, distilled water, forceps, tries which are used for pathogen growth on them, plastic sheet for covering of tries, marker which is used for labeling on try the name of the sample. Which were contains 100 maize grains and it was added in to the first Petridis which contains $70 \%$ of alcohol. And then it was turned into the next two and three consecutive Petridish that contains sterilized distilled water with the aid of forceps. And it was distributed on filter pepper. And $60 \mathrm{ml}$ of sterilized distilled water was added on displayed drain. Finally, the sterilized100 maize grains were displayed on sterilized drain with uniform distribution and it was leveled. Then the drain was covered with transparent film plastics and fixed with plaster and it was incubated for 10 days and the developments of ear rots were observed and the infected kernel frequency was calculated.

Procedures used for maize ear pathogens identification by moist chamber growing includes the following:

i. Prepare four Petri-dishes and add $75 \%$ ethanol on the first dish, add sterilized distilled water to the next three petri-dishes for disinfecting saprophytes on the maize cobs. Sterilization is the most important step in plant pathological experiment.

ii. Dry the sterilized maize cobs samples on filter pepper for minimizing moisture of outer seed water for accurate sample plating using sterilized forceps. Put pepper on tries and moist them using distilled water.

\subsection{Diagnosis of Bacterial and Fungal Diseases of Plant}

The materials we have used include:

i. Different diseased plant samples such as potato leaves, head cabbage, datura, ipomia leaves $\&$ avocado leaves.

ii. Laboratory instruments such as spatula, distilled water, PDA, NA, 70\% alchol, needle, laminal flow, Bunsen burner, filter pepper, autoclave, refrigerator, which are very important in plant pathology laboratory disease identification.

\subsection{Identification of Different Type of Fungus Group that Attacks Maize Cobs Under Artificial Growing Media per a Given Kernel}

About Four maize cobs were taken for laboratory experiment. Among those samples four individual kernels were randomly taken from individual maize cob and a total of sixteen individual kernels were taken independently. Then the kernels were spread on filter pepper and then all the sixteen independent samples of kernels were sequentially distributed on four artificial growing media with aid of forceps and Bunsen burner for sterilization. Then all the samples were labeled and incubated under lamina flow for three days. Finally the entire samples were visualized through our naked eyes.

\subsection{Diagnosis of Fungal and Bacterial Diseases in Laboratory under Class Basidiomycetes (Rust and Smut); Powdery Mildew and Zygomycetes}

Materials used when we diagnose the sample includemicroscope, glass, plant diseases sample, needle, bread mold sample, distilled water, culture media, moist chamber, beaker, pipette, slides and cover slip, aluminum-foils, lamina flow, forceps, Bunsen burner, alcohol, match, etc.

A Yellow dusty signs of begonia leaf rust was collected from field \& seen its symptom by necked eye. Then the spores of rust were taken from both sides of leaf and it was put under microscope slide that contains a drop of water for observing the sign of disease and under which family of the 
group based up on disease compendium list. Then the microscopes were adjusted and the structure of those fungi was observed. The sample from black powder sign of smut from the grass and white powdery mildew from the diseased plant was taken. It was put under microscope slide that contains a drop of water and covered with cover slip and then put under a microscope and the sample was observed and picture was drawn. The same portion of smut and powdery mildew was taken and isolate from the host plant and it was added in to four bicker that contain $1 / 3^{\text {rd }}$ of the bicker water content. It was incubated for $48 \mathrm{hrs}$ and observed after $48 \mathrm{hrs}$. Small portion of rhizopus fungi was taken from both bread and artificial media compare and contrast them for confirmation. Then the mycelium and sporulation of those funguses was identified.

\subsection{Bacterial Disease Diagnosis in Laboratory}

The sample of bacterial smear was taken by loop and it was put on clean slide. Then a tin bacterial smear was prepared. And it was dray without heat. The smear was flooded with crystal violate solution and it was leaved for $1 \mathrm{~min}$ then it was washed with running tap water for few sec. Again it was rinsed with iodine solution and leaved for $1 \mathrm{~min}$. Then the bacterial smear was washed with tape water and $95 \%$ of alcohol was applied and leaved for $30 \mathrm{sec}$. finally it was rinsed with tap water. And the bacterial smear was counter stained with $2.5 \%$ of safranin and leaved for $1 \mathrm{~min}$. Then it was washed with tap water and drayed without heat. Finally the smear was examined under compound microscopes.

\section{Result \& Discussion}

\subsection{Preparation of Culture Media Potato Dextrose Agar (PDA) for Fungi and Nutrient Agar (NA) for Bacteria}

We have prepared PDA media by mixing $7 \mathrm{gm} \& 250 \mathrm{ml}$ distilled water. We have prepared NA media by mixing $28 \mathrm{gm}$ $\& 1000 \mathrm{ml}$ distilled water. Autoclave it in autoclave machine and cool, pour on petri-dishes to prepare different isolates. In our case we have collect different leaves sample from field and sterilize them after that we plate them. We have accomplished all the procedure in laboratory with lab-PR equation steps. Mine result- appears in each sub-title for each specific plant diseases. We use PDA for fungal pathogens which can be grown on it after some period of time. All most all necro-tropic and bio-tropic fungi are grown on PDA agar, but bio-tropic fungi and bacterial diseases cannot grow on PDA agar. The best preferable method to diagnosis bio-tropic fungi is using direct leaf assay and blotting method on petri-dish. For bacterial disease identification we use NA agar. Disease identification starts from field \&go-through microscopic identification method in laboratory. For well experienced person identification can be done based disease symptom. But if disease is new use microscopic identification based on sign of the pathogen. If we are not well capable by simple observation of disease symptom, we use disease compendium and microscopic observation.

After sterilization of medium observe the medium in conical flask and pour it on petri-dish for solidification. After incubation period of 24-48 hrs for nutrient agar medium and 7 days for PDA observe the growth of any microbe on the surface of the medium.

\subsection{Identification of Major Maize Cob Diseases Samples Collected from SNNP Region and Jimma District}

Table 1. Maize cob diseases identified under laboratory condition

\begin{tabular}{|c|c|c|c|c|c|c|c|c|}
\hline Pathogn name & Fussarium & Aspergilous & Pencillium & Rhizopous & Fus+ASpg & ASPg+Penci & Fus+Penci & Others \\
\hline Symptom & White\&pink & Green/light yellow & Light blue & Blue black & $\begin{array}{l}\text { Combination } \\
\text { of the } 2\end{array}$ & $\begin{array}{l}\text { Combination } \\
\text { of the } 2\end{array}$ & $\begin{array}{l}\text { Combination of } \\
\text { the } 2\end{array}$ & \\
\hline Incidence & 10 & 31 & 3 & 1 & 23 & 4 & 9 & 19 \\
\hline
\end{tabular}

The material we have used for identifying which group of pathogen attack maize cob as follows: $70 \%$ alcohol, distilled water, tray, marker, covering plastic, needle, From our laboratory observation, we have seen disease symptoms on maize cob after planting 100 maize seeds on tray of plat. To calculate percentage of kernels infected by different types of maize cobs pathogens we use the formula of kernels infected by these specific pathogens divided by the total number of maize kernels. Based on this formula I have been calculated the following results. Based on our physical observation the most dominant pathogen are Aspergilous with incidence of $31 \%$, the combinstion of Fussarium +Aspergilous $23 \%$, by others (un-differentiated pathogens) 19\%, Fussarium 10\% and Fussarium+Pencilium 9\%. The rest pathogen incidence is very low or negligible. Our conclusion from this result is that the most dominant pathogen which affect maize cob were Aspergilose and the combination of Fussarium \&
Aspergilose, but it was minutely infected by Pencilium (3\%) and Rhizopus (1\%) pathogens.

\subsection{Diagnosis of Bacterial and Fungal Diseases of Plant}

In our laboratory result even if we are doing pure culture and isolate the specific pathogen in a pure culture it is difficult to get pure pathogenic growth because of contamination \& it is not grown at all. Because it is mixed with one or more contaminants, because it has not yet produced its characteristic fruiting structures and spores, or because the same disease could be caused by more than one similar looking pathogen and perhaps by some environmental factor. In which cases diagnosis by visual observation is not enough rather than isolation and identification of the pathogen are desirable in order to verify the diagnosis. From this result we had conclude that different pathogens need different media to complete this growth \& obligate pathogens 
did not grown on artificial media, they only grown on moist chamber or directly observed under compound microscope.

Table 2. Host crops, their diseases with caustive agents.

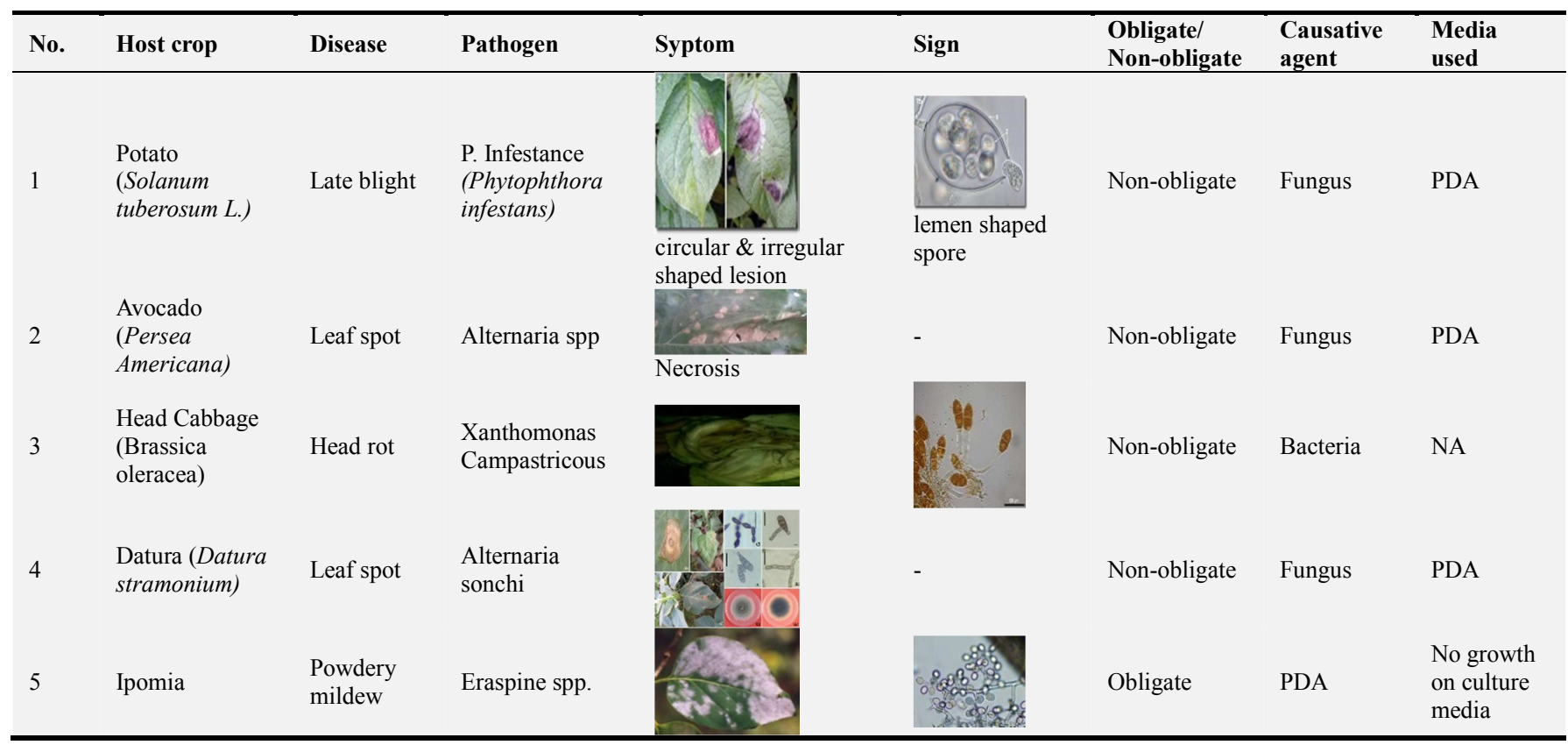

When pathogens grown on petri-dish in mixed form, we must done pathogen purification by single spore culture method. So, mine remark from this result is that disease identification began from the scratch whether it is pathogenic or non-pathogenic. If the cause were pathogenic which pathogenic group is that caused by. If it is impossible at species level we had gone down up to pathovar or race level using molecular tools.

\subsection{Identification of Different Type of Fungus Group that Attacks Maize Cobs under Artificial Growing Media per a Given Kernel}

From our isolates both the qualities as well as quantity of the seeds are dramatically reduced and it can also bear black rotten parts and loss of the size of seed in generals. Ear rots caused by various fungi, including Fusarium species, contribute to poor grain quality and contaminate grains with mycotoxins, which represent a threat to both human and animal health [33-34]. Because the type of mycotoxins found in grain is dependent on the toxigenic profile of the pathogenic populations in the field, knowledge on the prevailing species and mycotoxin levels may help to develop regional strategies aimed at preventing both the ear rot and stalk rot caused by the local populations [35]. A higher diversity of Fusarium species was found associated with maize kernels produced in the laboratory experiments. From the sample that we grow under artificial growing media all isolates are infected with Fusarium species. This is characterized by white and pink colors together on the media around and on the maize kernel. But the degree of pink colors is a little bit varies from sample to sample. This is because of different in Fusarium species.

Table 3. Comparison between different Fusarium species characterized by different colors.

\begin{tabular}{llll}
\hline Sample number & Fusarium & Fussarium (white + pink) With more pink Color & Fusarium (white +pink+ yellowish powder) \\
\hline 1 & $\sqrt{ }$ & & $\sqrt{ }$ \\
2 & $\sqrt{ }$ & Almost white \\
3 & $\sqrt{ }$ & $\sqrt{ }$ \\
4 & $\sqrt{ }$ & & \\
\hline
\end{tabular}

From the table we can discussed that a unit kernel of maize grain can be attacked by different Fusarium fungal species and the one which shows white, pink and same yellowish colors can tell us the given isolate can be affected by different fungal species other than white and pink colors of Fusarium species. So even if majority of ear rot of maize are caused by Fusarium, there is also the probability that have been be affected by other fungal groups within the same species.

\subsection{Diagnosis of Fungal and Bacterial Diseases in Laboratory under Class Basidiomycetes (Rust and Smut); Powdery Mildew and Zygomycetes}

From our first laboratory activity we can discuss that after the observation of yellow dusty particle of rust from the leaf of begonia under a microscope; we can conclude that among the different types of class basidiomycetes that Causes rust fungus and the immediate cause of rust is urediospores under class basidiomycetes. And we can also observe that the spore 
of this urediospores under class basidiomycetes which looks like massive accumulation of brown circular shape spores [43-44]. This is among the most destructive plant diseases that can have the capacity to travel long distance by wind or insects. This helps to easily transport and reproduce the new spores from source to new area. They have caused famines and ruined the economies of large areas, including entire countries. They have been most notorious for their destructiveness on grain crops, which can hinder each activity of plants like photosynthesis, and other enzymatic activity, are blocked and leads to complete death of plants in general. As we have seen in the laboratory there is a complete yellow dusty covering of leaves of plants. This shows that complete disorder of cellular activities and loss of turgidity in plant cells leads to complete death of plant cells.
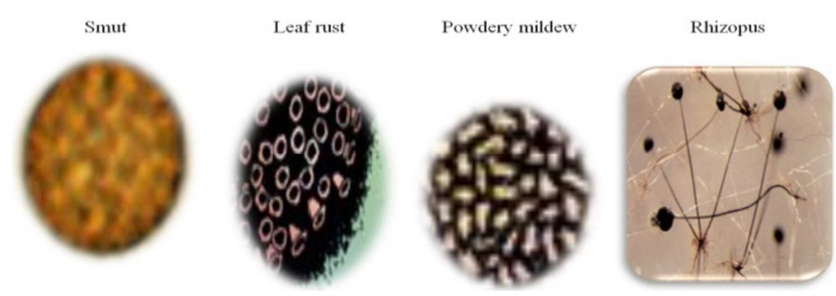

Figure 1. Foliar diseases of cereals seen under microscope.

The structures of Rahizopus from sample maize grain host or culture media is characterized by mass accumulations of spores on its mycelium but sample from bread mold is characterized by development of mycelium with rare existence of spores on the tips of mycelium. This is because the one which is grow on artificial media is produce well developed fruiting structure of spores since the growth media is more suitable and controlled including food sources that can easily utilized and ready to spray its spore to transport easily and reproduce itself. But those suitable conditions are found on breads as a result of this the development of its fruiting structure is rare and it takes time to develop and production of massive spores other than mycelium.

\subsection{Bacterial Disease Diagnosis in Laboratory}

From our observation of Gram staining method we have observe Gram negative bacteria which have pink color by following Gram staining reaction method. From $\mathrm{KOH}$ test we have observed Gram negative bacteria which have continuous string or mucilage like substance.

\section{Conclusion and Recommendation}

Plant disease diagnosis is a form of hypothesis testing, where the hypothesis is simply the identity of the disease, and a good diagnostician goes through multiple iterations of the scientific method (seeking evidence through testing that supports or refutes the hypothesis that $\mathrm{s} / \mathrm{he}$ generates). Diagnosis is one of the most important aspects of a plant pathologist's training. Identification of affected plants is one of the first steps in diagnosing a plant disease. From this laboratory work I had concluded that those fungal and bacterial diseases need their niche to grow and well identified. It is very difficult to identify plant diseases based on sign and symptom. It is very imperative to diagnosis plant disease by collaborating both conventional (using sign and symptom) and molecular methods [48].

\section{Acknowledgements}

First thanks to my Almighty God and St. Marry for making all things possible with giving me things which are very valuable for my life. Next I want to thank Hawassa university Plant pathology laboratory team to give laboratory materials and knowledge support specially Dr. Alemayehu Chala and Dr. Ferdu Azerefegn to sharpen me very well.

\section{References}

[1] Ferentinos, K. P., 2018. Deep learning models for plant disease detection and diagnosis. Computers and Electronics in Agriculture, 145, pp. 311-318.

[2] Singh, S. V. A. P., Sharma, A. C. S. and Rajvanshi, P., 2019. Deep Learning-Based Mobile Application for Plant Disease Diagnosis: A Proof of Concept With. Applications of Image Processing and Soft Computing Systems in Agriculture, p. 242.

[3] Wei, Y., Hu, W., Wang, Q., Zeng, H., Li, X., Yan, Y., Reiter, R. J., He, C. and Shi, H., 2017. Identification, transcriptional and functional analysis of heat-shock protein 90s in banana (M usa acuminata L.) highlight their novel role in melatonin-mediated plant response to $\mathrm{F}$ usarium wilt. Journal of pineal research, 62 (1), p. e12367.

[4] Nilsson, R. H., Hyde, K. D., Pawłowska, J., Ryberg, M., Tedersoo, L., Aas, A. B., Alias, S. A., Alves, A., Anderson, C. L., Antonelli, A. and Arnold, A. E., 2014. Improving ITS sequence data for identification of plant pathogenic fungi. Fungal Diversity, 67 (1), pp. 11-19.

[5] Mabberley, D. J., 2017. Mabberley's plant-book: a portable dictionary of plants, their classification and uses (No. Ed. 4). Cambridge University Press.

[6] Thurston, H. D., 2019. Sustainable practices for plant disease management in traditional farming systems. CRC Press.

[7] Mahlein, A. K., 2016. Plant disease detection by imaging sensors-parallels and specific demands for precision agriculture and plant phenotyping. Plant disease, 100 (2), pp. 241-251.

[8] Walkey, D. G., 2018. Virus diseases. In Onions and allied crops (pp. 203-224). CRC Press.

[9] Anand, K., Karuppanapandian, T. and Sinha, P. B., 2019. Isolation, Identification and Characterization of Fungi from Vinoba Bhave University Campus, Hazaribag District. In Innovation in Materials Science and Engineering (pp. 115-129). Springer, Singapore.

[10] Sefton, A., 2019. The biology of bacteria. Tutorial Topics in Infection for the Combined Infection Training Programme, p. 1.

[11] Ouchi, Y. and Kawahito, T., Nikon Corp, 2019. Microscope apparatus and storage medium storing microscope apparatus control program. U. S. Patent Application 10/241, 314. 
[12] Ongaro, D. G. and GHILARDI, M. P., Nakanishi Inc, 2019. Autoclave for sterilisation. U. S. Patent Application 10/179, 182.

[13] Li, S., Chen, Y., Huang, L. and Pan, D., 2014. Large-scale synthesis of well-dispersed copper nanowires in an electric pressure cooker and their application in transparent and conductive networks. Inorganic chemistry, 53 (9), pp. $4440-4444$.

[14] Distaso, T., Doyle, J., Venezia, M., Giuliani, M. and Mazzetti, C., Whirlpool Corp, 2015. Oven provided with aperture for air entry into its cavity. U. S. Patent $9,157,640$.

[15] Mochizuki, A., Okamoto, Y. and Yamada, F., PHC Holdings Corp, 2015. Incubator. U. S. Patent Application 29/489,063.

[16] Leal, C. R. L., Prates, R. A. and de Araújo, S. A., 2019. Automated Colony Counter for Single Plate Serial Dilution Spotting. Progress in Pattern Recognition, Image Analysis, Computer Vision, and Applications, p. 410.

[17] Romanhole, R. C., Ataide, J. A., Moriel, P. and Mazzola, P. G., 2015. Update on ultraviolet A and B radiation generated by the sun and artificial lamps and their effects on skin. International journal of cosmetic science, 37 (4), pp. 366-370.

[18] Nardo, M. and Franco, P., Hanna Instruments Inc, 2014. PH meter with surface ornamentation. U. S. Patent Application $29 / 449,072$

[19] Virr, A., Bath, A. R., Row, N. J., Kao, D., Hill, P. K., Earl, N. A., Verma, H. and Chen, J., ResMed Pty Ltd, 2019. Humidifier with a water tub within a pressurized chamber. U. S. Patent Application 10/279,141.

[20] Plack, L., Industriefarberei Faserveredlung Und Faserausruestung Wilhelm Plack Inhaber Ludwig Plack Ek, 2019. Wet treatment devices, in particular dyeing centrifuges, and a method for operating such a dyeing centrifuge. U. S. Patent Application 10/301,755.

[21] Ivanov, A. V., Bol'shakov, E. S., Apyari, V. V., Kozlov, A. A., Gorbunova, M. V. and Abdullaev, S. D., 2019. Analytical Response of Sensor Arrays Based on Photonic Crystals: Measurements of Diffuse Reflectance. Journal of Analytical Chemistry, 74 (2), pp. 198-204.

[22] Alam, M. A., Muhammad, G., Rehman, A., Russel, M., Shah, M. and Wang, Z., 2019. Standard Techniques and Methods for Isolating, Selecting and Monitoring the Growth of Microalgal Strain. In Microalgae Biotechnology for Development of Biofuel and Wastewater Treatment (pp. 75-93). Springer, Singapore.

[23] Jacob, P. E., Lindsten, F. and Schön, T. B., 2019. Smoothing with couplings of conditional particle filters. Journal of the American Statistical Association, (just-accepted), pp. 1-19.

[24] An, J. K. and Hwang, K. H., Samsung Electronics Co Ltd, 2019. Refrigerator. U. S. Patent Application 10/190,817.

[25] Youngkook, Y. O. O. N., LG Electronics Inc, 2019. Cooking device. U. S. Patent Application 10/222,058.

[26] Guidote Jr, A. M., Pacot, G. M. M. and Cabacungan, P. M., 2014. Low-cost magnetic stirrer from recycled computer parts with optional hot plate. Journal of Chemical Education, $92(1)$, pp. 102-105.
[27] Abo-Elyousr, K. A., Abdel-Hafez, S. I. and Abdel-Rahim, I. R., 2014. Isolation of Trichoderma and evaluation of their antagonistic potential against Alternaria porri. Journal of Phytopathology, 162 (9), pp. 567-574.

[28] Eevers, N., Gielen, M., Sánchez-López, A., Jaspers, S., White, J. C., Vangronsveld, J. and Weyens, N., 2015. Optimization of isolation and cultivation of bacterial endophytes through addition of plant extract to nutrient media. Microbial biotechnology, 8 (4), pp. 707-715.

[29] Mupangwa, W., Twomlow, S. and Walker, S., 2012. Reduced tillage, mulching and rotational effects on maize (Zea mays L.), cowpea (Vigna unguiculata (Walp) L.) and sorghum (Sorghum bicolor L.(Moench)) yields under semi-arid conditions. Field Crops Research, 132, pp. 139-148.

[30] Ali, F. and Yan, J., 2012. Disease resistance in maize and the role of molecular breeding in defending against global threat. Journal of integrative plant biology, 54 (3), pp. 134-151.

[31] Velásquez, A. C., Castroverde, C. D. M. and He, S. Y., 2018. Plant-pathogen warfare under changing climate conditions. Current Biology, 28 (10), pp. R619-R634.

[32] Misihairabgwi, J. M., Ezekiel, C. N., Sulyok, M., Shephard, G. S. and Krska, R., 2019. Mycotoxin contamination of foods in Southern Africa: A 10-year review (2007-2016). Critical reviews in food science and nutrition, 59 (1), pp. 43-58.

[33] Mudili, V., Siddaih, C. N., Nagesh, M., Garapati, P., Naveen Kumar, K., Murali, H. S., Yli Mattila, T. and Batra, H. V., 2014. Mould incidence and mycotoxin contamination in freshly harvested maize kernels originated from India. Journal of the Science of Food and Agriculture, 94 (13), pp. 2674-2683.

[34] Neme, K. and Mohammed, A., 2017. Mycotoxin occurrence in grains and the role of postharvest management as a mitigation strategies. A review. Food Control, 78, pp. 412-425.

[35] Magan, N., Medina, A. and Aldred, D., 2011. Possible climate-change effects on mycotoxin contamination of food crops pre-and postharvest. Plant Pathology, 60 (1), pp. $150-163$.

[36] Derevnina, L., Petre, B., Kellner, R., Dagdas, Y. F., Sarowar, M. N., Giannakopoulou, A., De la Concepcion, J. C., Chaparro-Garcia, A., Pennington, H. G., Van West, P. and Kamoun, S., 2016. Emerging oomycete threats to plants and animals. Philosophical Transactions of the Royal Society B: Biological Sciences, 371 (1709), p. 20150459.

[37] Poornima, S., Kavitha, S., Mohanavalli, S. and Sripriya, N., 2019, April. Detection and classification of diseases in plants using image processing and machine learning techniques. In AIP Conference Proceedings (Vol. 2095, No. 1, p. 030018). AIP Publishing.

[38] Agrios, G. N., 2005. Introduction to plant pathology. Elsevier Academic Press Publication, 922, pp. 23-37.

[39] Kamoun, S., Furzer, O., Jones, J. D., Judelson, H. S., Ali, G. S., Dalio, R. J., Roy, S. G., Schena, L., Zambounis, A., Panabières, F. and Cahill, D., 2015. The Top 10 oomycete pathogens in molecular plant pathology. Molecular plant pathology, 16 (4), pp. 413-434. 
[40] Toh, S. S. and Perlin, M. H., 2016. Resurgence of less-studied smut fungi as models of phytopathogenesis in the omics age. Phytopathology, 106 (11), pp. 1244-1254.

[41] Spanu, P. D., 2012. The genomics of obligate (and nonobligate) biotrophs. Annual review of Phytopathology, 50, pp. 91-109.

[42] Finckh, M. R., 2015. Organic small grain cereal disease management. Plant Diseases and their Management in Organic Agriculture, pp. 259-273.

[43] Hundie, B., Yirga, F., Kassa, D., Hailu, E., Negash, T., Tesfaye, T., Bacha, N., Shewaye, Y., Woldeab, G., Zegaye, H. and Tadesse, Z., 2018. Evaluation of Advanced Bread Wheat Lines for Field and Seedling Resistance to Stem Rust (Puccinia graminis f. sp. tritici). American Journal of Biological and Environmental Statistics, 4 (2), pp. 74-82.

[44] Hodson, D. P., Alemayehu, Y., Gilligan, C. A., Meyer, M., Allen, C., Millington, S., Thurston, W., Hort, M., Derso, E., Seid, J. and Bacha, N., 2018. Keeping Ahead of the Rust Menace: Emerging Wheat Rust Early Warning Systems in Ethiopia.
[45] Chowdhury, J., Henderson, M., Schweizer, P., Burton, R. A., Fincher, G. B. and Little, A., 2014. Differential accumulation of callose, arabinoxylan and cellulose in nonpenetrated versus penetrated papillae on leaves of barley infected with Blumeria graminis f. sp. hordei. New Phytologist, 204 (3), pp. 650-660.

[46] Crous, P. W., Verkley, G. J., Groenewald, J. Z. and Samson, R. A., 2009. Fungal biodiversity. Fungal biodiversity.

[47] Schaad, N. W., Jones, J. B. and Chun, W., 2001. Laboratory guide for the identification of plant pathogenic bacteria (No. Ed. 3). American Phytopathological Society (APS Press).

[48] Petti, C. A., Polage, C. R. and Schreckenberger, P., 2005. The role of 16S rRNA gene sequencing in identification of microorganisms misidentified by conventional methods. Journal of clinical microbiology, 43 (12), pp. 6123-6125. 